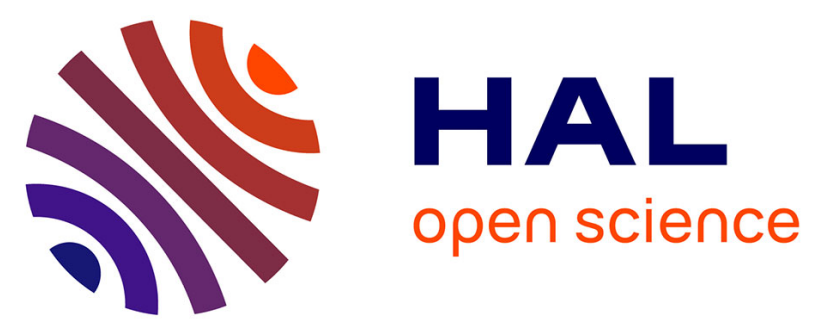

\title{
Development and validation of a UPLC-UV method for the quantification of thiopurine methyltransferase enzyme activity in human erythrocytes
}

S.M. Illamola, A.K. Echaabi, C. Mazeron, S. Deshayes, M.A. Loriot, N. Pallet

\section{- To cite this version:}

S.M. Illamola, A.K. Echaabi, C. Mazeron, S. Deshayes, M.A. Loriot, et al.. Development and validation of a UPLC-UV method for the quantification of thiopurine methyltransferase enzyme activity in human erythrocytes. Journal of Chromatography B - Analytical Technologies in the Biomedical and Life Sciences, 2019, 1113, pp.91 - 97. 10.1016/j.jchromb.2019.03.014 . hal-03487037

\section{HAL Id: hal-03487037 \\ https://hal.science/hal-03487037}

Submitted on 20 Dec 2021

HAL is a multi-disciplinary open access archive for the deposit and dissemination of scientific research documents, whether they are published or not. The documents may come from teaching and research institutions in France or abroad, or from public or private research centers.
L'archive ouverte pluridisciplinaire HAL, est destinée au dépôt et à la diffusion de documents scientifiques de niveau recherche, publiés ou non, émanant des établissements d'enseignement et de recherche français ou étrangers, des laboratoires publics ou privés.

\section{(ㅇ)(1) $\$$}

Distributed under a Creative Commons Attribution - NonCommerciall 4.0 International 
DEVELOPMENT AND VALIDATION OF A UPLC-UV METHOD FOR THE QUANTIFICATION OF THIOPURINE METHYLTRANSFERASE ENZYME ACTIVITY IN HUMAN ERYTHROCYTES

Illamola SM ${ }^{\text {a,\#,* }}$, Echaabi $\mathrm{AK}^{\mathrm{a}}$, Mazeron $\mathrm{C}^{\mathrm{a}}$, Deshayes $\mathrm{S}^{\mathrm{a}}$, Loriot MA ${ }^{\mathrm{a}, \mathrm{b}, \mathrm{c}}$, Pallet $\mathrm{N}$ $\mathrm{a}, \mathrm{b}, \mathrm{c}, \mathrm{d}$

a Service de Biochimie, Hôpital Européen Georges Pompidou, Assistance PubliqueHôpitaux de Paris, Paris, France

${ }^{\mathrm{b}}$ INSERM U1147, Centre Universitaire des Saints Pères, Paris, France

${ }^{c}$ Université Paris Descartes, Paris, France

${ }^{\text {d }}$ Service de Néphrologie, Hôpital Européen Georges Pompidou, Assistance PubliqueHôpitaux de Paris, Paris, France

\# Present address: Department of Experimental and Clinical Pharmacology, College of Pharmacy, University of Minnesota, Minneapolis, MN, USA

* Corresponding author: Silvia M. Illamola

Service de Biochimie, Hôpital Européen Georges Pompidou, Paris, France 20, rue Leblanc

75015 Paris, France

Tel. $\quad+330156092435$

Email:07silvia@gmail.com 


\section{ABSTRACT}

Thiopurines are drugs widely used for the treatment of autoimmune conditions, inflammatory bowel disease or acute lymphoblastic leukemia. Determination of thiopurine methyltransferase activity (TPMT), a major determinant of thiopurines toxicity, has been suggested before implementing thiopurine treatment. An ultraperformance liquid chromatography (UPLC) method was developed and validated for the quantification of TPMT enzyme activity based on the conversion of 6mercaptopurine (6-MP) to 6-methylmercaptopurine (6-MMP) using S-adenosyl-Lmethionine (SAM) as methyl donor in red blood cell lysates (RBC). This method was improved from the previous laborious high performance liquid chromatography (HPLC) method, using a lower volume of injection and with a shorter runtime.

After incubation and protein precipitation 6-MMP was separated on a HSS-T3 (2.1 x 50 $\mathrm{mm}, 1.8 \mu \mathrm{m})$ column and monitored by UV detection $(290 \mathrm{~nm})$. A change on the organic solvent used to dissolve 6-MP resulted in a reduction of interference by endogenous or non-enzymatic methylated 6-MMP. A full validation of the 6-MMP assay was performed according to the FDA and EMA guidelines. The method was linear from 0.125 to $2 \mathrm{nmol} / \mathrm{mL}$, with acceptable values of accuracy and precision.

The method was applied in 106 patients treated with thiopurines whose TPMT activity was previously quantified by HPLC. Evaluation through Bland-Altman plot showed that TPMT activities were in agreement between both methods.

Key words: UPLC-UV; thiopurine S-methyltransferase activity; TPMT; 6-MP; 6-MMP 


\section{INTRODUCTION}

Thiopurine drugs, azathioprine (AZA) (which is rapidly and largely transformed into 6mercaptopurine (6-MP) after being absorbed) and 6-MP, are cytotoxic and immunosuppressive drugs widely used for the treatment of autoimmune conditions, inflammatory bowel disease or acute lymphoblastic leukemia (1). The common side effects of these drugs are leukopenia and hepatotoxicity $(2,3)$.

Thiopurines are inactive pro-drugs that require to be metabolised to exert their activity (4). There are two main enzymes involved on the metabolism pathways of 6-MP. Hypoxanthine-guanine phosphoribosyltransferase (EC 2.4.2.8; HGPRT), which produces the cytotoxic 6-thioguanine nucleotides (6-TGNs) that are incorporated into DNA and RNA. Thiopurine S-methyltransferase (EC 2.1.1.67; TPMT), which produces 6-methylmercaptopurine (6-MMP) (inactive metabolite) and methylthioinosine monophosphate (meTIMPT), a strong inhibitor of de novo purine synthesis (5).

Regardless their efficacy, thiopurines have a large interindividual variability in terms of efficacy and toxicity, mainly due to genetic polymorphisms that affect TPMT activity (6). Large studies on Caucasian population have reported a trimodal distribution of TPMT activity, with $89 \%$ of them having high TPMT activities (homozygous wild-type alleles), $11 \%$ with intermediate TPMT activities (heterozygous with one allele affected), and $0.3 \%$ showing low activities (mutations in both alleles) (7).

Individuals with low TPMT activity who receive standard dosages of 6-MP are more likely to have myelotoxicity (8). Otherwise, patients with high TPMT activity accumulate 6-MMP, a metabolite associated with hepatotoxicity at concentrations higher than $5700 \mathrm{pmol} / 8 \times 10^{8}$ red blood cell (RBC) (8). Therefore, individuals should be screened for TPMT activity before starting thiopurine therapy $(9,10)$. 
Although genotyping could be a reliable method to detect non-functional TPMT alleles, the correlation between genotypic and phenotypic assessment is imperfect (11), and testing for TPMT activity in RBC should be preferred before implementing thiopurine treatment.

TPMT activity was initially measured by a radiochemical assay (12). Lennard and Jacqz-Aigrain introduced the first non-radioactive HPLC methods for the determination of TPMT activity $(13,14)$. In a second time, several HPLC methods with UV and fluorescence detection have been published (15-22). More recently, the use of LCMS/MS methods to measure TPMT activity has emerged (23-26). Most methods are based on the enzymatic methylation of 6-MP by TPMT in red blood cell lysates with Sadenosyl-L-methionine (SAM) as methyl donor.

We have modified an existing HPLC-UV method for the measurement of TPMT activity (18) to a novel, simpler and rapid UPLC-UV assay resulting in better reproducibility and higher accuracy in measuring enzyme activities.

\section{MATERIAL AND METHODS}

\section{Chemicals and reagents}

6-Mercaptopurine (6-MP), dithiothreitol (DTT), allopurinol, S-adenosyl-L-methionine (SAM), potassium phosphate monobasic dihydrate and potassium phosphate dibasic were purchased from Sigma-Aldrich (Saint-Quentin Fallavier, France). 6methylmercaptopurine (6-MMP) was obtained from Alfa Aesar (Lancashire, United Kingdom). Seventy percent perchloric acid was from VWR (Fontenay sous Bois, France). Sodium hidroxide and trifluoroacetic acid (TFA) were from Prolabo (Paris, France). Acetonitrile (ACN), MS/MS grade, was obtained from Biosolve (Orleans, 
France). The water was produced locally by a Milli-Q system (Millipore; Saint-Quentinen-Yvelines, France). Drug-free plasma samples were obtained from the Etablissement Français du Sang (Hôpital Européen Georges-Pompidou; Paris, France).

\section{Equipment}

Liquid chromatography analyses were carried out on an Acquity UPLC H-Class system (Waters; Milfor, MA) with a cooling autosampler and column oven. For the separation, a reversed-phase Acquity UPLC® HSS T3 column $(2.1$ x 50 mm i.d., $1.8 \mu \mathrm{m})$ (Waters, Saint-Quentin, France) protected with an Acquity UPLC® HSS T3Vanguard ${ }^{\mathrm{TM}}$ precolumn (2.1 x $5 \mathrm{~mm}$ i.d., 1.8 particle size) were used. Ultraviolet (UV) detection was performed on a Waters Acquity UPLC $®$ UV detector a11tuv714a. Instrument control and data acquisition and processing were handled by a computer equipped with Empower Pro (Waters Version 6.20).

Haematocrit was measured directly in a Sysmex XN-9000 analyser.

\section{Chromatographic conditions}

Compounds separation was performed using a stepwise gradient at a flow rate of 0.5 $\mathrm{mL} / \mathrm{min}$. A binary gradient system was used consisting of $0.1 \%(\mathrm{v} / \mathrm{v})$ trifluoroacetic acid in water as eluent A and acetonitrile as eluent B. The separation of compounds was carried out over 3 min. At time zero the flow consisted of $95 \%$ of mobile phase A, which was linearly decreased to $80 \%$ within 3 minutes. The column was then washed with $100 \%$ of acetonitrile for 2 minutes. The last 4 minutes the column was reconditioned with $95 \%$ of mobile phase $\mathrm{A}$ and $5 \%$ of mobile phase $\mathrm{B}$, before the next injection. The column temperature was set to $40^{\circ} \mathrm{C}$ and sample temperature at $4^{\circ} \mathrm{C}$. The detection wavelength was set up at $290 \mathrm{~nm}$ absorbance. 


\section{Sample collection, storage and RBC lysate preparation}

Blood samples were collected into EDTA tubes and stored at $4^{\circ} \mathrm{C}$ before analysis. They were prepared as described previously (12). Briefly, $7 \mathrm{~mL}$ of whole blood collected in EDTA tube was centrifuged at $800 \mathrm{~g}$ for $10 \mathrm{~min}$ at $+4^{\circ} \mathrm{C}$ to isolate red cells. Plasma, leukocytes and the upper layer of the erythrocytes were removed. After, erythrocytes were washed twice with $4 \mathrm{~mL}$ of $0.154 \mathrm{M} \mathrm{NaCl}$ and centrifuged for $10 \mathrm{~min}$ at $800 \mathrm{~g}$. For the determination of the haematocrit, $2 \mathrm{~mL}$ of red cells were resuspended in $2 \mathrm{~mL}$ of $0.154 \mathrm{M} \mathrm{NaCl} .2 \mathrm{~mL}$ of solution of red blood cells were lysed with $8 \mathrm{~mL}$ of cold distilled water and centrifuged at $13000 \mathrm{~g}$ for $10 \mathrm{~min}$ at $+4^{\circ} \mathrm{C}$. The supernatant was kept at $-80{ }^{\circ} \mathrm{C}$ until analysis.

\section{Incubation and UPLC analysis}

6-MP solution was prepared immediately prior to use by dissolving 6-MP in $0.1 \mathrm{~N}$ $\mathrm{NaOH}$. Solutions of SAM, allopurinol and dithiothreitol in water were kept at $-80^{\circ} \mathrm{C}$ for 1 month or less.

Briefly, samples were incubated at $37^{\circ} \mathrm{C}$ for $1 \mathrm{~h}$ in a shaking water bath, in a final volume of $155 \mu 1$. Samples consisted of $25 \mu$ l of potassium phosphate buffer (ph 7.5; $1 \mathrm{M}$ ), $25 \mu 1$ of a mixture containing SAM (final concentration: $0.7 \mathrm{mM}$ ), allopurinol (an inhibitor of xantihine oxidase, final concentration: $33 \mathrm{mM}$ ) and DTT (to protect the thiopurine substrate from oxidation, final concentration: $59 \mathrm{mM}$ ), and $5 \mu$ l of 6-MP

solution (final concentration $58 \mathrm{mM}$ ). The reaction was started by adding $100 \mu \mathrm{l}$ of haemolysate. Samples were incubated 1 hour, and the reaction was stopped by adding $50 \mu \mathrm{L}$ of $70 \%$ perchloric acid. The remnant was centrifuged for $10 \mathrm{~min}$ at $13.000 \mathrm{rpm}$ after protein precipitation. The clear $10 \mu \mathrm{l}$ of the supernatant were analysed by UPLCUV without further treatment. 


\section{Validation of TPMT activity assay}

The linearity and proportionality of the TPMT enzyme activity were analysed at 10 different incubation times (from 0 to $180 \mathrm{~min}$ ) with a fixed amount of lysate; and at fixed time the amount of lysate ranged from 0 to $200 \mu \mathrm{L}$. All points were analysed on triplicate.

Intra-day precision was determined by TPMT activity replicate analysis $(n=6)$ of one single frozen sample in one analytical run. Inter-day precision was determined by TPMT activity analysis on five different days. Precision was expressed as the relative standard deviation (RSD, \%) of calculated activities.

\section{Validation of 6-MMP assay}

A full validation of the 6-MMP assay was performed according to the FDA and EMA guidelines for validation of bioanalytical assays $(27,28)$. 6-MMP solution was prepared immediately prior to use in $0.1 \mathrm{~N} \mathrm{NaOH}$.

Standard curves of 6-MMP ( 0.125 to $2 \mathrm{nmol} / \mathrm{mL}$ of 6-MMP) were prepared by addition of appropriate amounts of 6-MMP to lysate. To prepare the quality control samples (QC), similar addition process of appropriate amounts of 6-MMP to lysate was done. Finally, four QC levels were obtained: a lower limit of quantification (LLOQ) level, one within three times the LLOQ (LQC), one around 50\% of the calibration curve range (MQC), and another at least at $75 \%$ of the upper calibration curve range (HQC): 0.125 , $0.375,0.75$ and $1.75 \mathrm{nmol} / \mathrm{mL}$ of 6-MMP. Both calibration standards (CAL) and QC samples, except for the addition of substrate 6-MP, were treated and analysed as analysis samples. 


\section{Linearity and lower limit of quantification}

A total of six non-zero calibration samples were prepared and analysed in six separate runs. Each calibration standard curve was calculated and fitted by linear regression (without weighting factor analysis) of the areas of 6-MMP against the spiked concentrations. Slope, Y-intercept and correlation coefficient were calculated using Empower Pro software. The back-calculated calibration concentrations should be within $\pm 15 \%$ of the nominal value, except for LLOQ, for which $\pm 20 \%$ was acceptable. The distribution of the variance over the calibration range (homo/heteroscedasticity) was evaluated by applying the Levene Test $(\alpha=5 \%)$.

The lower limit of quantification (LLOQ) should be at least 5 times the blank response, with and accuracy and precision within $\pm 20 \%$. The blank was analysed ten times, and the mean area was compared with the area obtained from the LLOQ samples.

\section{Accuracy and precision}

Intra-assay accuracy and precision were determined by replicate analysis $(n=6)$ of each of the four QCs $(0.125,0.375,0.75$ and $1.75 \mathrm{nmol} / \mathrm{mL})$ performed on the same day. Inter-day accuracy and precision were determined by analysis of the same QC level on 6 separate analytical runs. Precision was expressed as the relative standard deviation (RSD, \%) of the concentrations calculated within a single run (intra-assay) and between different assays (inter-assay). The accuracy of the method was referred as the percentage deviation of the calculated concentration from the known concentrations; it was expressed as the absolute value of the relative error (ERR, \%) of the calculated concentrations. Accuracy and precision should be within the $\pm 20 \%$ for the LLOQ and $\pm 15 \%$ for all other concentrations. 


\section{Selectivity}

Selectivity was investigated by the analysis of 6 different samples. The aim was to verify the absence of any interfering substance at the retention time of 6-MMP. If it exists, it should be less than $20 \%$ of the LLOQ.

Recovery

The extraction recovery was determined by comparing the peak areas of 6-MMP in two extracts: one obtained from the extracted spiked samples, and the other by adding 6MMP to extracted lysates (representing $100 \%$ of extraction recovery). Percentage (\%) recovery was calculated at $\mathrm{LQ}$, and $\mathrm{HQ}$ concentration in triplicate.

\section{Carryover}

The presence of carryover was assessed by injecting two double blank samples after last standard of the calibration curve. The analysis was repeated three times. As recommended (28), the signal of the blank samples should not be greater than $20 \%$ of the LLOQ.

\section{Stability}

The stability of SAM, allopurinol and DTT solutions at $-80^{\circ} \mathrm{C}$ was previously analysed in our laboratory. Stability of 6-MMP solution in $\mathrm{NaOH} 0.1 \mathrm{~N}$ when stored at $-80^{\circ} \mathrm{C}$ for up to three months was evaluated by comparing peak areas at two different concentrations $(0.25$ and $1.5 \mathrm{nmol} / \mathrm{mL})$ over time. The stock solutions were considered stable when $90-110 \%$ of the nominal concentration was found compared to the freshly prepared stock solution.

The final extract stability was determined after storage at $4^{\circ} \mathrm{C}$ by re-injection of extracts kept in the autosampler at $4^{\circ} \mathrm{C}$ for $24 \mathrm{~h}$ and $72 \mathrm{~h}$. The study was performed in a pool used 
during routine practice with a known TPMT activity of $12 \mathrm{nmol} / \mathrm{h} / \mathrm{mL} \mathrm{RBC}$, and in 5 different patient samples that covered all TPMT range activity.

\section{Comparison of HPLC and UPLC methods}

We determined TPMT activity in erythrocytes in 106 individuals. The same samples were simultaneously analysed by the HPLC method currently used in our laboratory (18). The nonparametric regression procedure of Passing and Bablok was used for method comparison (29). Agreement between methods was presented using the Bland Altman differences plot $(30,31)$.

\section{RESULTS AND DISCUSSION}

\section{Analytical development and chromatography}

The development of the UPLC-UV method for the determination of TPMT activity was based on the HPLC-UV method used in the laboratory (18). All enzymatic conditions were kept as the original method (e.g., concentration of 6-MP and SAM, nature of the buffer in which the reaction takes place, incubation conditions), with the exception of the solvent used for the preparation of 6-MP and 6-MMP solutions.

Regarding chromatographic separation, two different columns were tested, Bridged Ethylene Hybrid (BEH) and HSS-T3. Under our final chromatographic conditions, we chose HSS-T3 $(2.1 \times 50 \mathrm{~mm}, 1.8 \mu \mathrm{m})$ over BEH, on account of better peak shape and resolution. The injection volume $(10 \mu \mathrm{L})$ was significantly lower than that used in the original method $(100 \mu \mathrm{L})(18)$, as well as in any other published HPLC-UV methods, and similar than that used in published LC-MS/MS methods.

Sample preparation was slightly modified because, under the conditions of the initial method (18) (extraction with a mixture of ethanol and methanol-0.1 M HCl (80:20)), a 
precipitated was formed in the samples. Although several conditions for sample preparation have been proposed (21), the extraction with $70 \%$ perchloric acid proposed by Khalil et al (20) was initially selected and finally applied.

Under the conditions set forth, 6-MMP was successfully separated from human plasma components and other elements synthetized during the reaction, and quantitated. The retention time of 6-MMP was $1.89 \mathrm{~min}$ (Figure 1), and the total run time was $9 \mathrm{~min}$. It represents a significant decrease from the run time of the previous HPLC method (40 min), and it is in line with the available LC-MS/MS methods (23-26), with run times around $7 \mathrm{~min}$.

\section{Enzymatic reaction}

Due to the limited solubility of 6-MP in aqueous solutions, the organic solvent dimethyl sulphoxide (DMSO) was used in the initial method. However, as previously reported by several authors $(13,20,21)$, its use implies a significant 6-MMP formation in samples incubated without SAM (blank samples) as a result of non-enzymatic conversion or presence of endogenous SAM. The suitability of the use of DMSO as a solvent for the preparation of 6-MP solutions was studied and compared with $\mathrm{NaOH} 0.1 \mathrm{~N}$. Incubated blank samples containing 6-MP dissolved in DMSO $(n=5)$ and in $\mathrm{NaOH} 0.1 \mathrm{~N}(\mathrm{n}=5)$, but without co-substrate SAM were analysed. The formation of 6-MMP in blank samples when 6-MP was dissolved in DMSO and $\mathrm{NaOH} 0.1 \mathrm{~N}$ was $27 \%(\mathrm{CV}=11.3 \%)$ and $14 \%$ $(\mathrm{CV}=13.3 \%)$, respectively, of that when samples were incubated with SAM. Therefore, $\mathrm{NaOH}$ was chosen as solvent. Under these conditions, the analysis of 137 different samples showed that the generation of 6-MMP in blank samples varied from $0 \%$ to $19 \%$ $(\mathrm{CV}=136.1 \%)$ of that when samples were incubated with SAM. Therefore it confirmed that the formation of 6-MMP in blank samples is matrix dependent. Due to the variable 
amount of non-enzymatic 6-MMP originated in blank samples, for each sample, a blank incubated without SAM was included.

Either with respect to the lysate concentration $(0-200 \mu 1 /$ assay $)$ or time incubation $(0-$ $180 \mathrm{~min}$ ), the formation of 6-MMP was linear. The average equations were $y=108.19 x$ - 11.54.9 $\left(\mathrm{r}^{2}=0.9877, \mathrm{y}=6\right.$-MMP area, $\mathrm{x}=$ volume of packed $\left.\mathrm{RBC}\right)$, and $\mathrm{y}=164.7 \mathrm{x}$ +2011.2 $\left(\mathrm{r}^{2}=0.9902, \mathrm{y}=6\right.$-MMP area, $\mathrm{x}=$ incubation time), respectively (Figure 2). Intra-assay precision of TPMT activity was $1.4 \%$, and inter-assay precision, determined by measuring TPMT activity on five different runs, was $3.7 \%$.

\section{Validation of 6-MMP assay}

\section{Linearity and lower limit of quantification}

The application of Levene statistic test showed a significant difference $(\mathrm{p}<0.05)$ between variances of each standard concentration, thus the procedure was found to be heteroscedastic. As proposed by Almeida et al (32) the best weighting factor was chosen according to the percentage relative error (\%RE), and it was $1 /$ concentration. Calibration curve was linear over the range of 0.125 to $2 \mathrm{nmol} / \mathrm{mL}$ with $\mathrm{r}^{2}>0.99$. The limit of quantification was the lowest concentration in the calibration curve $(0.125$ $\mathrm{nmol} / \mathrm{mL})$.

\section{Accuracy and precision}

Intra- and inter-assay accuracy and precision are summarized in Table 1. The accuracy for intra- and inter-assay ranged from 0.2 to $1.9 \%$ and from 0.4 to $0.9 \%$, respectively. Intra- and inter-assay precisions were always lower than $5.9 \%$ and $4.3 \%$, respectively. The values of accuracy and precision prove the fidelity and the reproducibility of the method. 


\section{Selectivity}

The selectivity of the method was acceptable as the absence of interferences in the blank samples analysed was verified.

Recovery

The extraction procedure of the initial method (18) was slightly modified in order to eliminate the colour precipitate observed sometimes after the extraction. Oselin et al (21) compared different extraction methods published previously in the literature and their in-house developed methods. Although in-house developed extraction with acetonitrile provided increased method sensitivity, it assumes an evaporation phase, thus increasing the complexity of the process. Consequently, extraction with $70 \%$ perchloric acid was performed based on Khalil et al (20). By using this method, the mean absolute recoveries $( \pm \mathrm{SD})$ for 6-MMP were $102.4 \%( \pm 1.4 \%)$ and $103.8 \%( \pm 0.4 \%)$ at 0.375 and $1.75 \mathrm{nmol} / \mathrm{mL}$, respectively. The present pre-treatment procedure was selective, efficient and reproducible, allowing a reduction of time in the sample preparation procedure, as well as in the cost of the analysis, compared to Oselin et al method (21). Hence, this method was finally selected.

Carryover

Injection of two double blank samples immediately after last standard of the calibration curve showed no carryover (Figure 1B) of the UPLC-UV method.

\section{Stability}

Stock solution of 6-MMP in $\mathrm{NaOH} 0.1 \mathrm{~N}$ at two tested concentrations were stable at $80^{\circ} \mathrm{C}$ up to 3 months. Peak area of 6-MMP freshly stock solutions at 0.25 and 1.5 $\mathrm{nmol} / \mathrm{mL}$ was 2565 and 14091 , respectively. After 3 months at $-80^{\circ} \mathrm{C}$, peak area of $6-$ 
MMP was $+0.19 \%$ (at $0.25 \mathrm{nmol} / \mathrm{mL}$ ) and $-0.21 \%$ (at $1.5 \mathrm{nmol} / \mathrm{mL}$ ) of the nominal 6MMP concentration of the initial stock solution.

Previous studies showed TPMT activity is stable in plasma at $-80^{\circ} \mathrm{C}$ for up to 6 months at $-80^{\circ} \mathrm{C}(14)$.

The stability of the final extract, at different concentrations, was within $15 \%$ limit when compared with initial concentrations (Table 2). They were considered stable up to $72 \mathrm{~h}$ stored at $4^{\circ} \mathrm{C}$.

\section{Comparison of HPLC and UPLC methods}

TPMT activity in erythrocytes was determined in 106 individuals by both HPLC and UPLC methods. Both HPLC and UPLC methods represented TPMT activities that were normally distributed (Kolmogorov-Smirnov, $\mathrm{p}<0.05$ ), and the mean \pm standard deviation (range) measured by HPLC and UPLC was $12.7 \pm 4.11 \mathrm{nmol} / \mathrm{h} / \mathrm{mL} \mathrm{RBC} \mathrm{(3.2}$

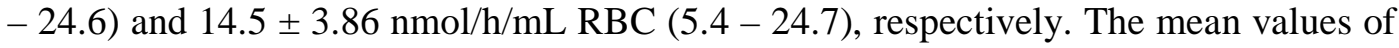
TPMT activities between both methods were significantly different (t-test, $\mathrm{p}<0.05$ ). This difference between the methods could be due to the difference on the formation of 6MMP when 6-MP was dissolved in DMSO and $\mathrm{NaOH}$. The correlation of both methods was evaluated by Passing \& Bablok regression and the equation was UPLC $=2.103+$ 0.987HPLC, $r=0.806$ (Pearson correlation coefficient) (Figure 3). The 95\% confidence interval (95\% CI) of slope and intercept were 0.88-1.01 and 0.51-3.26 nmol/h/mL RBC, respectively. Passing-Bablok regression revealed that HPLC and UPLC TPMT activities were correlated.

Although the means of both methods were different, and the analysis of Passing-Bablok revealed that both methods were correlated, the evaluation of its agreement was performed by Bland-Altman analysis. Differences between both methods were not 
normally distributed (Shapiro-Wilk test, $\mathrm{p}<0.05$ ). Therefore, logarithmic transformation was used for the Bland-Altman analysis. Bland-Altman plots of the logarithmic differences between the HPLC and UPLC methods are shown in Figure 4. The 95\% limit of agreement (95\% LOA) was -0.23 to 0.09 . The $94.3 \%$ of samples were within the range of $95 \%$ LOA (Figure 4A). Represented by the ratio of difference between to methods to average (Figure 4B), the mean bias was $-6.9 \%$, and the $95 \%$ LOA was $25.9 \%$ to $12.1 \%$. The bias (mean difference) was -0.07 , and almost constant for all the measured concentrations, with the exception of very low values, with a negative value at low concentrations. However, the small variation (-25.9 to $12.1 \%)$ between HPLC and UPLC methods was unlikely to have a clinical impact. Therefore, TPMT activity measured by HPLC and UPLC methods were in agreement with each other.

\section{CONCLUSIONS}

We developed and validated a simple and rapid UPLC-UV assay for the measure of TPMT activity in whole blood. To our best knowledge, this is the first fully validated UPLC-UV method for the quantification of TPMT activity.

The analytical procedure of this new method is easier and less labour intensive. Additionally, the assay uses a lower volume of injection and has a significant lower time of analysis.

This assay results in a reduction of interference by endogenous or non-enzymatic methylated 6-MMP, which is taken into account by the use of a blank. Therefore, it is more reproducible and it has a better analytical selectivity to identify patients with TPMT deficiency than the previously method. This method can be easily implemented for the quantification of TPMT activity in the clinical practice. 


\section{REFERENCES}

[1] Chouchana L, Narjoz C, Beaune P, Loriot MA, Roblin X. Review article: the benefits of pharmacogenetics for improving thiopurine therapy in inflammatory bowel disease. Aliment Pharmacol Ther. 35 (2012) 15-36.

[2] Kerstens PJ, Stolk JN, Hilbrands LB, van de Putte LB, De Abreu RA, Boerbooms AM. 5-nucleotidase and azathioprine-related bone-marrow toxicity. Lancet. 342 (1993) 1245-1246.

[3] Dutz JP, Ho VC. Immunosuppressive agents in dermatology. An update. Dermatol Clin. 16 (1998) 235-251.

[4] Derijks LJ, Gilissen LP, Hooymans PM, Hommes DW. Review article: thiopurines in inflammatory bowel disease. Aliment Pharmacol Ther. 24 (2006) 715729.

[5] Fotoohi AK, Coulthard SA, Albertioni F. Thiopurines: factors influencing toxicity and response. Biochem Pharmacol. 79 (2010) 1211-1220.

[6] Weinshilboum R. Thiopurine pharmacogenetics: clinical and molecular studies of thiopurine methyltransferase. Drug Metab Dispos. 29 (2001) 601-605.

[7] Weinshilboum RM, Sladek SL. Mercaptopurine pharmacogenetics: monogenic inheritance of erythrocyte thiopurine methyltransferase activity. Am J Hum Genet. $32(1980)$ 651-662.

[8] Dubinsky MC, Lamothe S, Yang HY, Targan SR, Sinnett D, Theoret Y, et al. Pharmacogenomics and metabolite measurement for 6-mercaptopurine therapy in inflammatory bowel disease. Gastroenterology. 118 (2000) 705-713.

[9] Agence Nationale de Sécurité du Médicament et des Produits de Santé. http://base-donnees- 
publique.medicaments.gouv.fr/affichageDoc.php?specid=64841852\&typedoc=R .

Last Accessed: 08.16.2018

[10] Annotation of FDA Label for azathioprine and TPMT. PharmgKB. https://www.pharmgkb.org/labelAnnotation/PA166104782. Last Accessed: 10.25.2013

[11] Chouchana L, Narjoz C, Roche D, Golmard JL, Pineau B, Chatellier G et al. Interindividual variability in TPMT enzyme activity: 10 years of experience with thiopurine pharmacogenetics and therapeutic drug monitoring. Pharmacogenomics 15 (2014) 745-757.

[12] Weinshilboum RM, Raymond FA, Pazmino PA. Human erythrocyte thiopurine methyltransferase: radiochemical microassay and biochemical properties. Clin Chim Acta. 85 (1978) 323-333.

[13] Lennard L, Singleton HJ. High-performance liquid chromatographic assay of human red blood cell thiopurine methyltransferase activity. J Chromatogr B Biomed Appl. 661 (1994) 25-33.

[14] Jacqz-Aigrain E, Bessa E, Medard Y, Mircheva Y, Vilmer E. Thiopurine methyltransferase activity in a French population: h.p.l.c. assay conditions and effects of drugs and inhibitors. Br J Clin Pharmacol. 38 (1994) 1-8.

[15] Kroplin T, Weyer N, Gutsche S, Iven H. Thiopurine S-methyltransferase activity in human erythrocytes: a new HPLC method using 6-thioguanine as substrate. European Journal of Clinical Pharmacology. 54 (1998) 265-271.

[16] Ganiere-Monteil C, Pineau A, Kergueris MF, Azoulay C, Bourin M. Thiopurine methyl transferase activity: new extraction conditions for high-performance liquid chromatographic assay. J Chromatogr B Biomed Sci Appl. 727 (1999) 235-239. 
[17] Boulieu R, Sauviat M, Dervieux T, Bertocchi M, Mornex JF. Phenotype determination of thiopurine methyltransferase in erythrocytes by HPLC. Clin Chem. 47 (2001) 956-958.

[18] Anglicheau D, Sanquer S, Loriot MA, Beaune P, Thervet E. Thiopurine methyltransferase activity: new conditions for reversed-phase high-performance liquid chromatographic assay without extraction and genotypic-phenotypic correlation. J Chromatogr B. 773 (2002) 119-127.

[19] Ford LT, Berg JD. Determination of thiopurine S-methyltransferase activity in erythrocytes using 6-thioguanine as substrate and a non-extraction liquid chromatographic technique. J Chromatogr B. 798 (2003) 111-115.

[20] Khalil MN, Erb N, Khalil PN, Escherich G, Janka-Schaub GE. Interference free and simplyfied liquid chromatography-based determination of thiopurine Smethyltransferase activity in erythrocytes. J Chromatogr B. 821 (2005) 105-111.

[21] Oselin K, Anier K, Tamm R, Kallassalu K, Maeorg U. Determination of thiopurine S-methyltransferase (TPMT) activity by comparing various normalization factors: Reference values for Estonian population using HPLC-UV assay. J Chromatogr B. 834 (2006) 77-83.

[22] Karim H, Appell ML, Fotoohi A. Comparison of three methods for measuring thiopurine methyltransferase activity in red blood cells and human leukemia cells. J Chromatogr B. 939 (2013) 80-85.

[23] Mei S, Li X, Gong X, Zhang X, Li X, Yang L, et al. Comparison of 6mercaptopurine with 6-thioguanine for the analysis of thiopurine S-methyltransferase activity in human erythrocyte by LC-MS/MS. Biomed Chromatogr. 31 (2017). 
[24] Pecher D, Dokupilova S, Zelinkova Z, Peppelenbosch M, Mikusova V, Mikus

P. Determination of thiopurine S-methyltransferase activity by hydrophilic interaction liquid chromatography hyphenated with mass spectrometry. J Pharm Biomed Anal. 142 (2017) 244-251.

[25] Wiwattanakul S, Prommas S, Jenjirattithigarn N, Santon S, Puangpetch A, Pakakasama S, et al. Development and validation of a reliable method for thiopurine methyltransferase (TPMT) enzyme activity in human whole blood by LC-MS/MS: An application for phenotypic and genotypic correlations. J Pharm Biomed Anal. 145 (2017) 758-764.

[26] Ma J, Sies CW, Pike LS. Analytical and clinical validation of an LC-MS/MS method to measure thiopurine S-methyltransferase activity by quantifying d3-6MMP. Clin Biochem. 54 (2018) 100-105.

[27] European Medicines Agency. Guideline on bioanalytical method validation 2011.http://www.ema.europa.eu/docs/en_GB/document_library/Scientific_guideline/ 2011/08/WC500109686.pdf.

[28] U.S. Food and Drug Aministration: Center for Drug Evaluation and Research. http://www.labcompliance.de/documents/FDA/FDA-Others/Laboratory/f-507bioanalytical-4252fnl.pdf.

[29] Passing H, Bablok. A new biometrical procedure for testing the equality of measurements from two different analytical methods. Application of linear regression procedures for method comparison studies in clinical chemistry, Part I. J Clin Chem Clin Biochem. 21 (1983) 709-720.

[30] Bland JM, Altman DG. Statistical Methods for Assessing Agreement between Two Methods of Clinical Measurement. Lancet. 1 (1986) 307-310. 
[31] Bland JM, Altman DG. Measuring agreement in method comparison studies. Stat Methods Med Res. 8 (1999) 135-160.

[32] Almeida AM, Castel-Branco MM, Falcao AC. Linear regression for calibration lines revisited: weighting schemes for bioanalytical methods. J Chromatogr B Analyt Technol Biomed Life Sci. 774 (2002) 215-222. 
(A)

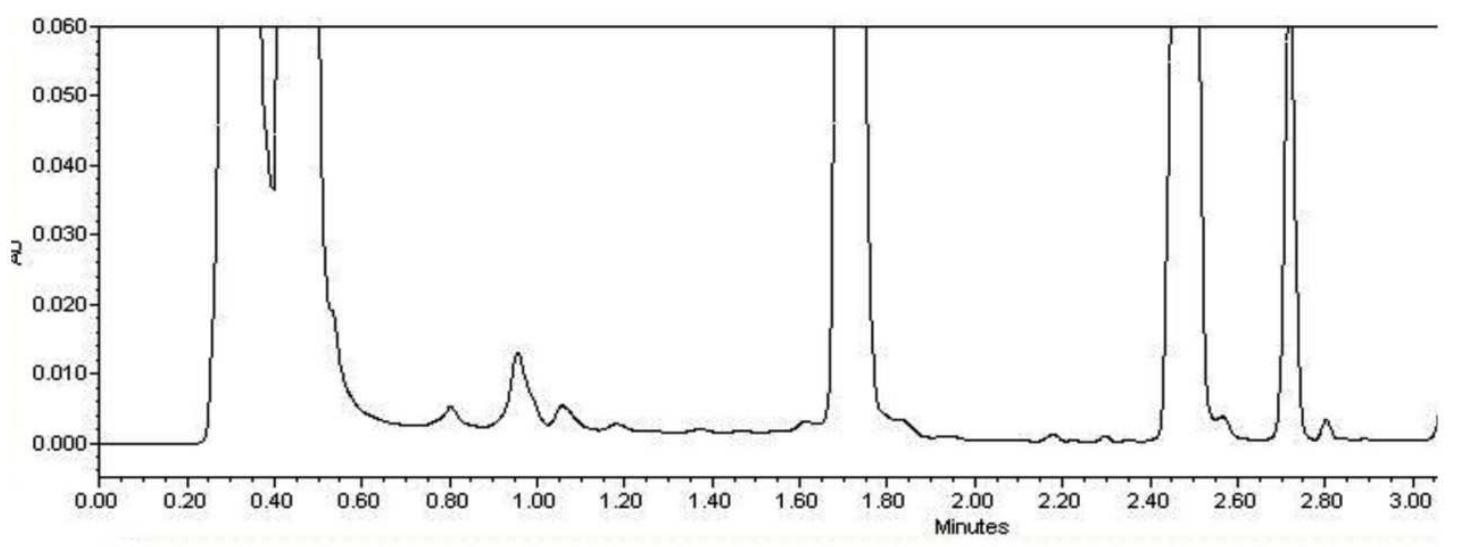

(B)

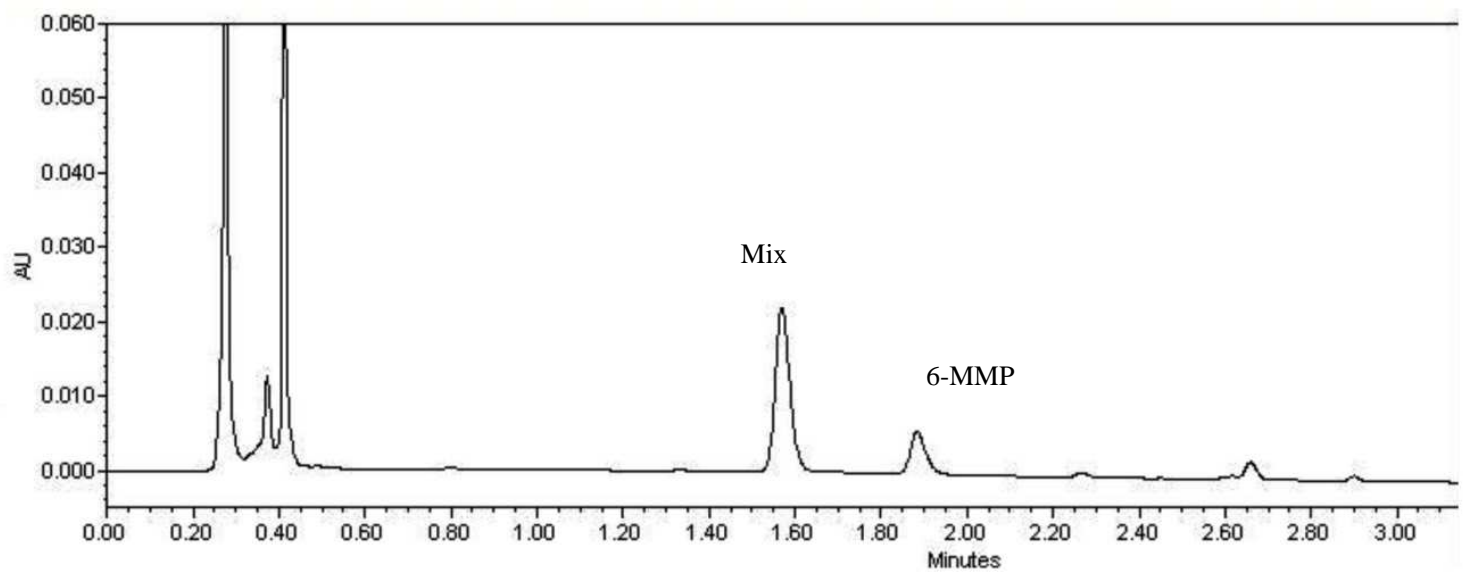

(C)

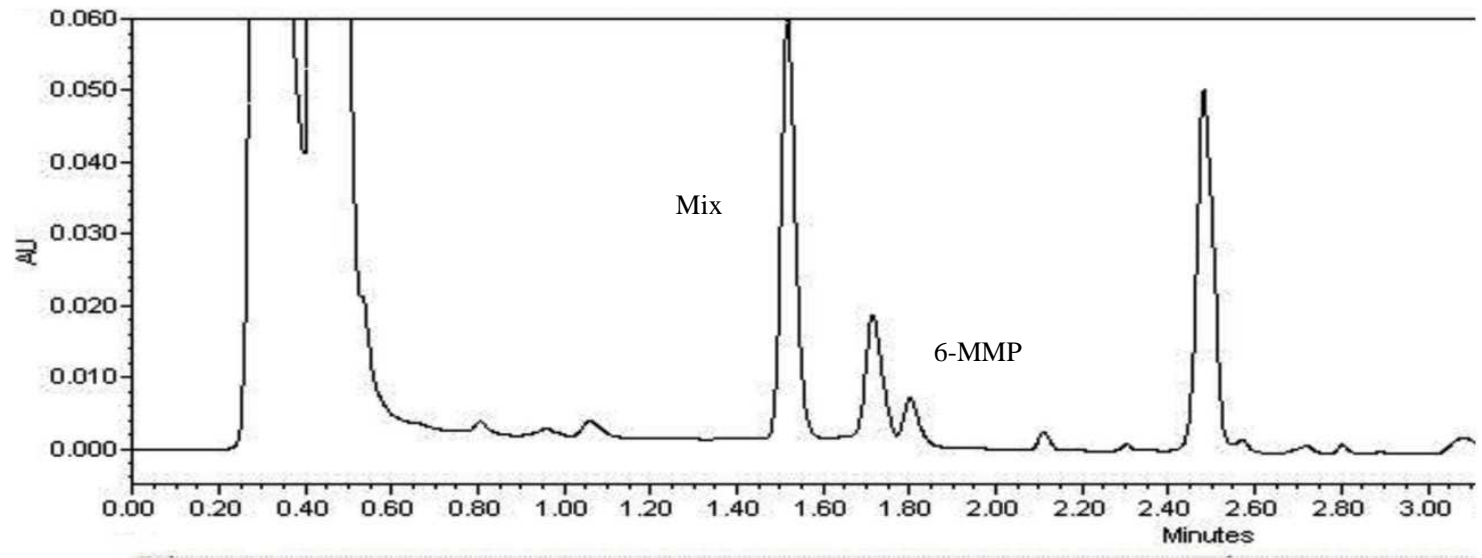


Figure 1. Representative chromatograms of (A) blank plasma, (B) highest point of the calibration standard curve $(2 \mathrm{nmol} / \mathrm{mL}),(\mathrm{C})$ plasma from a patient monitored of TPMT activity, showing a retention time of 6-MMP (6-methylmercaptopurine) of 1.89 minutes. *Mix: mixture containing SAM, allopurinol, DTT and 6-MP solution. 
(A)

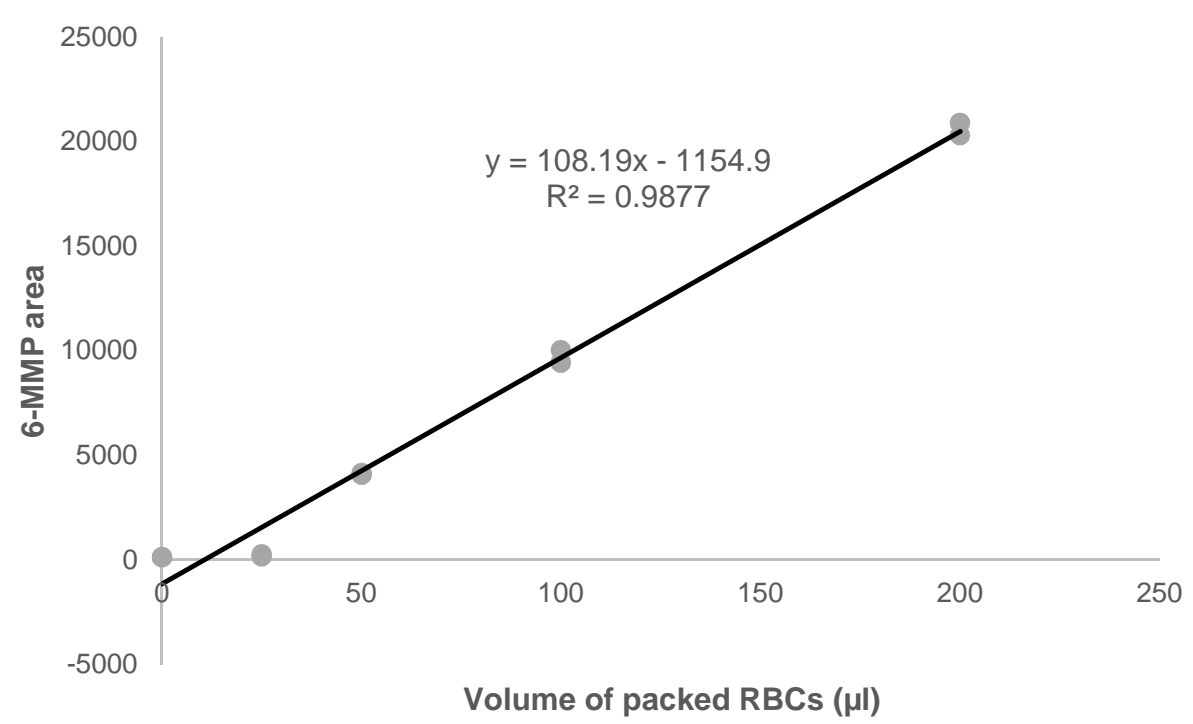

(B)

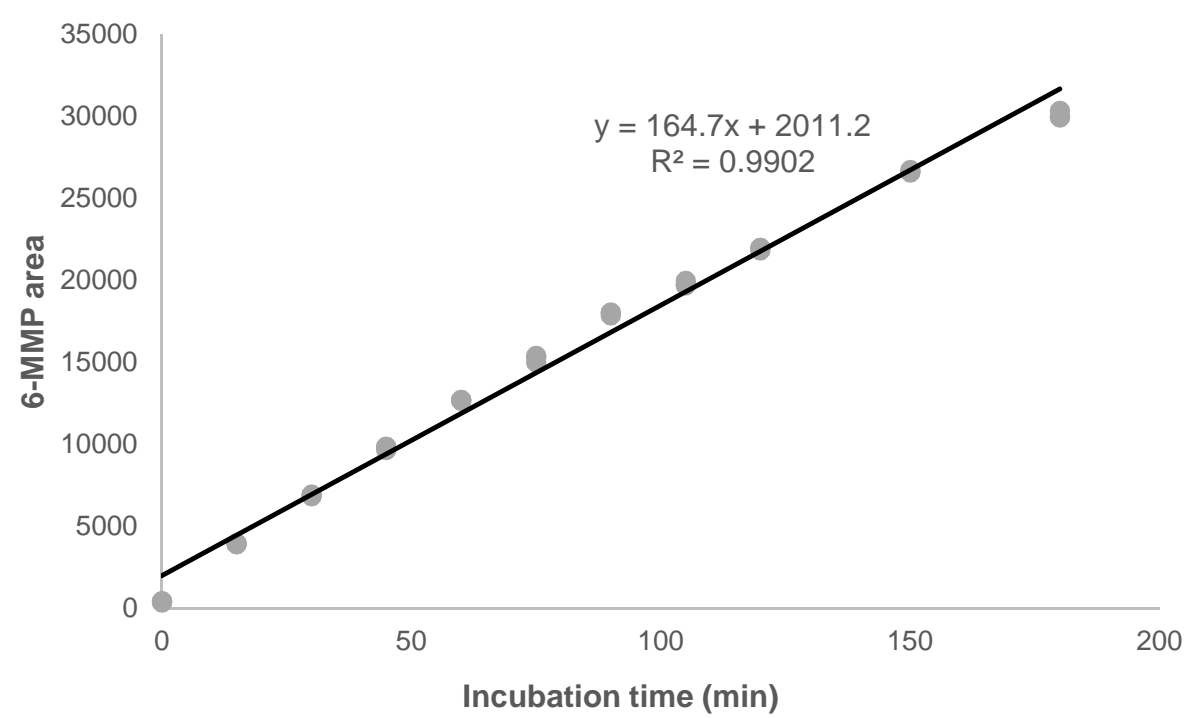

Figure 2. Effect of increasing quantities of erythrocyte lysate (A) and incubation time (B) on TPMT activity. 


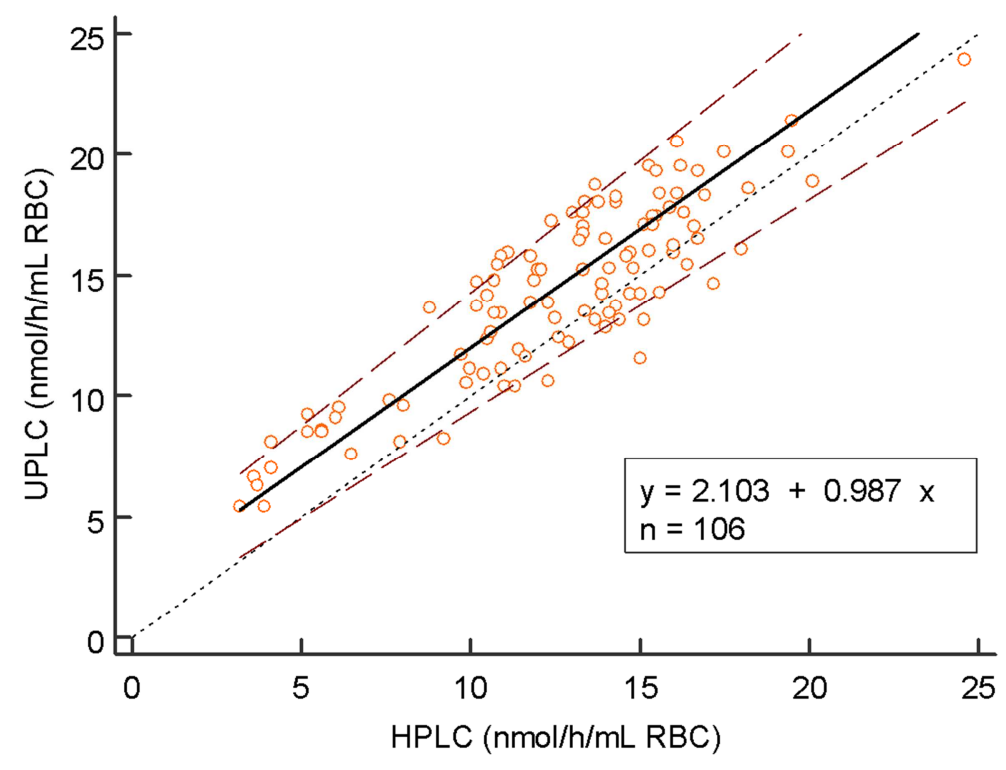

Figure 3. Passing-Bablok regression between HPLC and UPLC methods in the determination of TPMT activity 
(A)

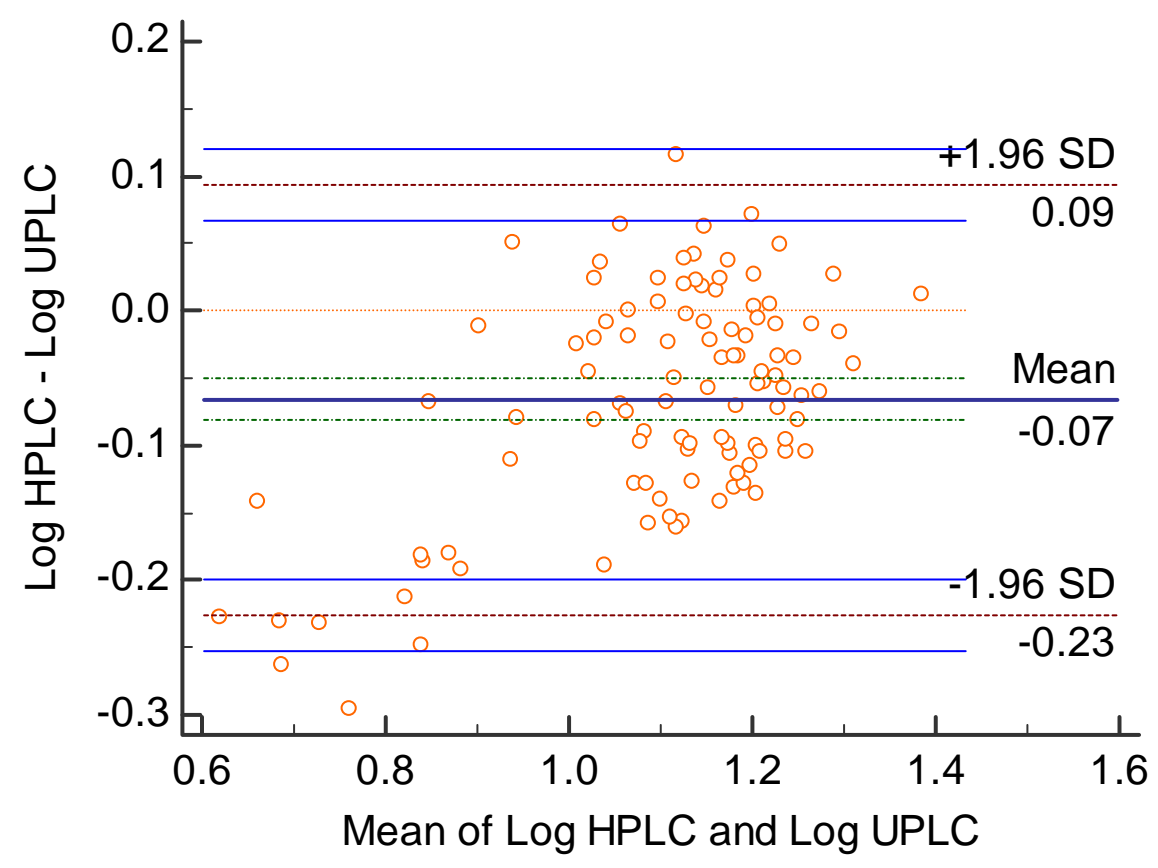

(B)

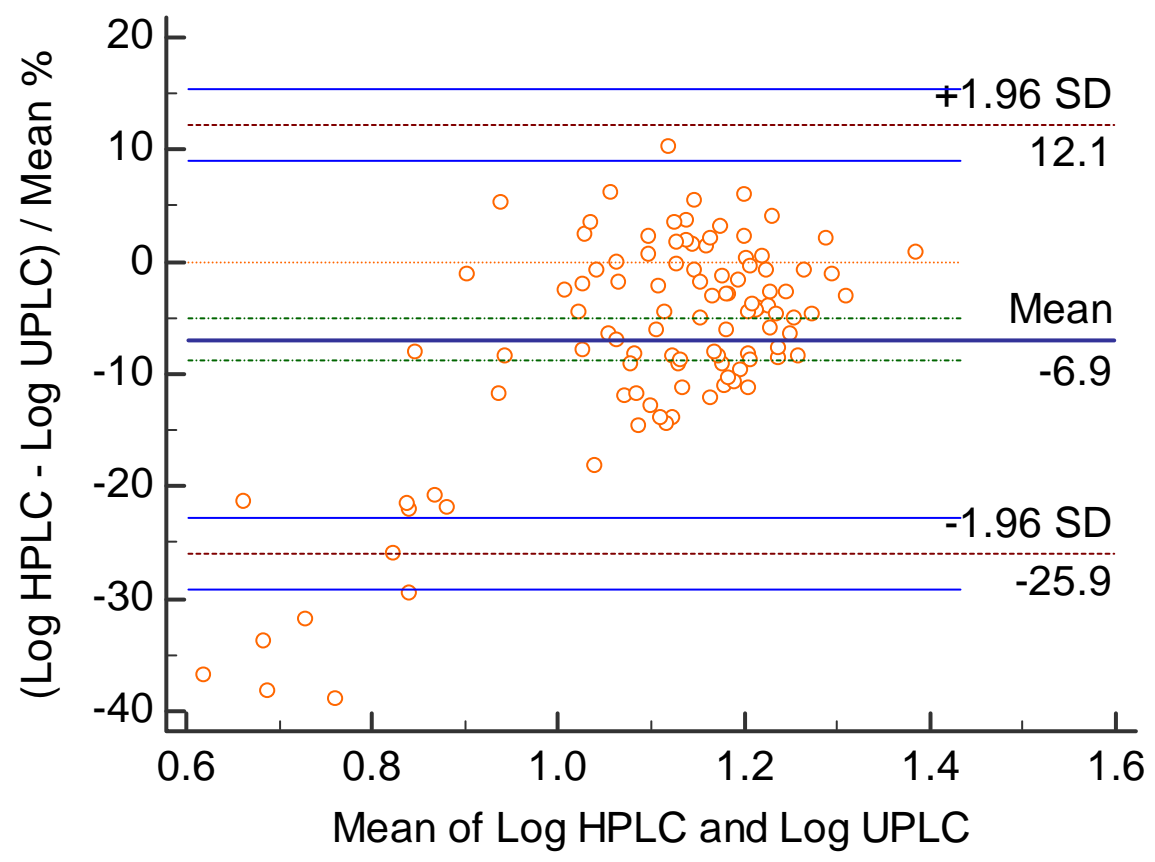

Figure 4. Bland-Altman plots showing agreement between HPLC and UPLC methods in the determination of TPMT activity 
Table 1. Intra- and inter-day accuracy and precision of 6-MMP in the haemolysate.

\begin{tabular}{lccccc}
\hline & \multicolumn{2}{c}{ Intra-assay (n=6) } & \multicolumn{2}{c}{ Inter-assay (n=18) } \\
& $\begin{array}{c}\text { Concentration } \\
(\mathbf{n m o l} / \mathbf{m L})\end{array}$ & $\begin{array}{c}\text { Accuracy } \\
(\mathbf{E R R}, \%)\end{array}$ & $\begin{array}{c}\text { Precision } \\
(\text { RSD, \%) }\end{array}$ & $\begin{array}{c}\text { Accuracy } \\
(\mathbf{E R R}, \%)\end{array}$ & $\begin{array}{c}\text { Precision } \\
(\mathbf{R S D}, \%)\end{array}$ \\
\hline LLOQ & 0.125 & 1.9 & 5.9 & 0.9 & 3.6 \\
LQ & 0.375 & 1.3 & 2.3 & 0.4 & 4.3 \\
MQ & 0.75 & 0.5 & 0.5 & 0.5 & 2.4 \\
HQ & 1.75 & 0.2 & 1.4 & 0.8 & 1.3 \\
\hline
\end{tabular}


Table 2. Stability of the final extract.

\begin{tabular}{|c|c|c|c|c|c|}
\hline \multirow[t]{2}{*}{$\begin{array}{l}\text { Matrix/ } \\
\text { Condition }\end{array}$} & \multicolumn{3}{|c|}{$\begin{array}{l}\text { Mean measured TPMT } \\
\text { activity }(\mathrm{nmol} / \mathrm{h} / \mathrm{mL} \text { RBC) }\end{array}$} & \multicolumn{2}{|c|}{ Mean deviation (\%) } \\
\hline & Initial & $24 \mathrm{~h}$ & $72 \mathrm{~h}$ & $24 h$ & $72 \mathrm{~h}$ \\
\hline \multirow{6}{*}{$\begin{array}{l}\text { Final } \\
\text { extract/ } 3 \\
\text { days, } 4^{\circ} \mathrm{C}\end{array}$} & 12.1 & 12.9 & 12.6 & 6.71 & 3.43 \\
\hline & 6.3 & 6.1 & 7.1 & -1.96 & 13.0 \\
\hline & 11.7 & 11.6 & 12.5 & -0.58 & 7.13 \\
\hline & 12.6 & 12.8 & 13.0 & 1.76 & 3.28 \\
\hline & 14 & 14.3 & 13.9 & 1.72 & -0.83 \\
\hline & 20.7 & 21.0 & 21.7 & 1.33 & 4.85 \\
\hline
\end{tabular}

